\title{
A steady-state stomatal model of balanced leaf gas exchange, pÿhydraulics and maximal source sink flux
}

\section{Hölttä, Teemu Samuli}

2017

Hölttä , T S , Lintunen, A M , Chan , T, Mäkelä-Carter , A A \& Nikinmaa , E H 2017 , ' A steady-state stomatal model of balanced leaf gas exchange, hydraulics and maximal pÿsource sink flux ' , Tree Physiology , vol. 37 , no. 7 , pp. 851-868 . https://doi.org/10.1093/treephys/tpx011

http://hdl.handle.net/10138/311772

https://doi.org/10.1093/treephys/tpx011

acceptedVersion

Downloaded from Helda, University of Helsinki institutional repository.

This is an electronic reprint of the original article.

This reprint may differ from the original in pagination and typographic detail.

Please cite the original version. 
1 A steady state stomatal model of balanced leaf gas exchange, hydraulics 2 and maximal source-sink flux.

3

\author{
Teemu Hölttä*, Anna Lintunen, Tommy Chan, Annikki Mäkelä, Eero Nikinmaa \\ University of Helsinki, Department of Forest Sciences P.O. Box 27, 00014 University of \\ Helsinki, Finland
}

Keywords: $\mathrm{CO} 2$ assimilation, phloem transport, photosynthesis, stomatal conductance, transpiration, xylem transport

*Corresponding Author: Teemu Hölttä (teemu.holtta@helsinki.fi)

\begin{abstract}
Trees must simultaneously balance their $\mathrm{CO}_{2}$ uptake rate via stomata, photosynthesis, the transport rate of sugars and rate of sugar utilization in sinks while maintaining a favourable water and carbon balance. We demonstrate using a numerical model that it is possible to understand stomatal functioning from the viewpoint of maximizing the simultaneous photosynthetic production, phloem transport, and sink sugar utilization rate under the limitation that transpiration driven hydrostatic pressure gradient set for those processes. A key feature in our model is that non-stomatal limitations to photosynthesis increase with decreasing leaf water potential and/or increasing leaf sugar concentration and are thus coupled to stomatal conductance. Maximizing the photosynthetic production rate using a numerical steady-state model leads to stomatal behaviour that is able to reproduce the wellknown trends of stomatal behaviour in response to e.g. light, VPD, ambient $\mathrm{CO}_{2}$ concentration, soil water status, sink strength, and xylem and phloem hydraulic conductance. We show that our results for stomatal behaviour are very similar to the solutions given by the earlier models of stomatal conductance derived solely from gas exchange considerations. Our modeling results also demonstrate how the "marginal cost of water" in the unified stomatal conductance model and the optimal stomatal model could be related to plant structural and physiological traits, most importantly, the soil-to-leaf hydraulic conductance.
\end{abstract}

\title{
Introduction
}

Water and carbon exchange occur in opposing directions in a tightly controlled manner at the vegetation-atmosphere interphase through stomatal openings in the leaves of vascular plants. The loss of water from the leaves to the atmosphere is replaced with water flow from soil through the xylem, while part of the xylem sap flow is needed for turgor driven transport of the assimilated carbohydrates in the phloem from leaves to sites of consumption in sugar sinks. Xylem transport and water uptake by roots have to maintain the rate of water loss by transpiration from the leaves, or stomatal closure will have to occur to prevent excessive decrease in xylem water potential and the associated plant dehydration and run-away embolism in the xylem (Tyree and Sperry, 1988). Similarly, symplastic osmotic concentrations need to match the hydrostatic pressure drop in the leaves and phloem transport 
and utilization of photosynthates in sinks have to match the rate of carbon assimilation in photosynthesis, or carbohydrate accumulation will eventually force stomatal closure and down-regulation of photosynthesis (Paul and Foyer, 2001).

While the exchange of water between leaves and atmosphere is determined solely by stomatal conductance and water vapour concentration difference (VPD) between the intercellular spaces and ambient air, the situation for $\mathrm{CO}_{2}$ exchange is more complex. The $\mathrm{CO}_{2}$ concentration difference between the ambient air and intercellular spaces is dependent on the rate of $\mathrm{CO}_{2}$ consumption inside the leaf mesophyll cells. There are complex feedbacks between the amount of light energy, leaf internal $\mathrm{CO}_{2}$ concentration and the internal state of the leaf, e.g. its water and carbohydrate relations (Paul and Pellny, 2003) which are further connected to the state of whole tree water and carbon status through xylem and phloem transport (Nikinmaa et al., 2013). While the trade-off between $\mathrm{CO}_{2}$ assimilation and water vapour loss has been extensively treated in connection with plant water relations, the connection between transpiration driven hydrostatic pressure and the photosynthesis driven osmotic pressure has not, although the latter has implications for assimilate transport and to their use in growth (e.g. DeSchepper and Steppe, 2010; Hölttä et al., 2010). Due to the osmotic properties of the most common form of assimilated sugars, there is a relatively narrow margin between the feasible apoplastic water pressure and symplastic sugar concentration to maintain turgor pressure within physiologically reasonable limits, and indeed, disruptions in this balance have been suggested as one major cause of drought related mortality (McDowell et al., 2011; Sevanto et al., 2014).

Stomatal responses to environmental and internal factors have been under rigorous study for the past decades, but the topic is still far from being understood. Our present understanding on stomatal behaviour is mainly based on relations of gas exchange at the leaf surfaces (Ball et al., 1987; Medlyn et al., 2011). Stomata appear to respond to VPD and light in a manner which optimizes water loss per carbon gain in a given leaf environment (e.g. Hari and Mäkelä 2003; Medlyn et al., 2011). In addition, factors not directly connected to leaf level relations such as soil water availability (eg. Tuzet et al., 2003; Duursma et al., 2008), changes in xylem conductivity (Sperry et al., 1993), and the utilization of photosynthates in sinks (Körner, 2003) are known to play an important role in stomatal regulation. It is well acknowledged that many whole-plant level traits are involved in stomatal regulation, but a coherent framework that includes all of these is lacking. It has also become evident during recent years that besides the changes in stomatal conductance, also changes in mesophyll conductance and the biochemistry of photosynthesis contribute to the rate of photosynthetic production. The changes in mesophyll conductance are known to vary according to e.g. environmental conditions, even on time scales as short as minutes (e.g. Flexas et al., 2008, 2012; Kaiser et al., 2015) and the changes in mesophyll conductance and stomatal conductance appear to be tightly coupled (e.g. Gago et al., 2016). Also the biochemistry of photosynthesis, i.e. carboxylation efficiency, has been found to change diurnally even during non-water stressed conditions (e.g. Guo et al., 2009, Buckley and Diaz Espejo, 2015). Although the details on how the stomatal and non-stomatal factors controlling photosynthesis are co-regulated are still missing, stomatal conductance and mesophyll conductance have typically been found to change in parallel (Flexas et al., 2008).

In this study, we develop a whole-tree-level theoretical framework to explain stomatal behaviour, and present a model linking source (leaf gas exchange) and sink (sugar utilization and soil water uptake) relations through xylem and phloem transport. The model is used to demonstrate how stomatal gas exchange is constrained by soil water status, sink strength, 
xylem and phloem transport, and the state of photosynthetic machinery as well its sensitivity to local water and sugar status, in addition to the leaf level environmental conditions. The model employed is a steady state simplification of the dynamic model used in Nikinmaa et al. (2013), where it was demonstrated that the stomatal behaviour of trees could be predicted by maximizing the instantaneous phloem mass transport rate. In relation to Nikinmaa et al. (2013), the steady state formulation presented here is more straightforward, easier to implement, and allows a closed form solution of the equations. We use the model to demonstrate that the stomatal behaviour of trees can be understood quite far in terms of maximizing the photosynthetic rate while being able to transport the assimilated sugars through the phloem and utilize the sugars in sinks in steady state (Hölttä and Nikinmaa, 2013).

A key feature in our model is that it allows for the impact of source-sink linking to stomatal behaviour through the feedback between non-stomatal limitations to photosynthesis mediated by leaf water and/or carbohydrate status. We use the term non-stomatal limitations to photosynthesis to describe the decrease in photosynthesis rate for a given internal leaf $\mathrm{CO}_{2}$ concentration, light level and temperature. The non-stomatal limitations arise due to e.g. metabolic impairment of photosynthesis and/or decrease in mesophyll conductance (Flexas and Medrano, 2002). In our model framework the feedback between stomatal and nonstomatal limitations to photosynthesis arises as stomatal opening monotonically decreases leaf water potential and increases leaf sugar concentration (as shown in the results section).

Our approach offers a coherent framework of stomatal regulation within whole tree physiology. The predictions for stomatal control using our model approach span over a wider range of environmental, structural and physiological conditions in comparison to earlier stomatal control models. Our model predictions for stomatal conductance are demonstrated to be very similar to the predictions given by the "unified stomatal control model" (e.g. Medlyn et al., 2011) and the "optimal stomatal conductance model" (e.g. Hari and Mäkelä, 2003).

\section{Results}

Leaf transpiration and $\mathrm{CO}_{2}$ exchange rates started to decrease, and leaf osmotic concentration started to increase shortly after the notching and girdling experiments (See Supplementary Materials Fig. S3). Leaf water potential started to decrease in the notching experiment while it started to increase in the girdling experiment (Fig. S3). The ratio between the gross photosynthesis rate $(A)$ and leaf internal $\mathrm{CO}_{2}$ concentration $\left(C_{i}\right)$ (representing $\phi$ in Equation 5) was found to be well described by leaf osmotic concentration when all of the measurement points were pooled together (Fig. $2 \mathrm{a}, \mathrm{R}^{2}=0.60, \mathrm{~N}=58, \mathrm{p}<0.001$ ) as was assumed in our model formulation (Equation 5). The $A / C_{i}$ ratio correlated also with leaf water potential, when all of the experiments were pooled together (Fig. $2 \mathrm{~b}, \mathrm{R}^{2}=0.32, \mathrm{~N}=58, \mathrm{p}<0.001$ ). However, the correlation between water potential and $A / C_{i}$ ratio was not as strong as the correlation between leaf osmotic concentration and $A / C_{i}$. This was due to the girdling experiments where the correlation between leaf water potential and osmotic potential was broken down (not shown) due to sink limitation, and where a strong correlation was found between $A / C_{i}$ and osmotic concentration $\left(\mathrm{R}^{2}=0.44, \mathrm{~N}=22, \mathrm{p}<0.001\right)$, but not between $A / C_{i}$ and leaf water potential $\left(\mathrm{R}^{2}=0.02, \mathrm{~N}=18, \mathrm{p}>0.05\right)$.

Figure 3 demonstrates steady state relations in leaf (source), phloem and stem base (connected to the sink in roots) when stomatal conductance changes using the base case parameterization shown in Table 1. Leaf internal $\mathrm{CO}_{2}$ concentration increases with increasing 
stomatal conductance (Fig. 3a). Simultaneously, the non-stomatal limitations to photosynthesis increase, i.e. $\phi$ decreases (Fig. 3a) due to an increase in leaf osmotic concentration (Fig. 3b). Leaf osmotic concentration increases in line with decreasing water value that allows the steady-state transport of the photosynthesized sugars in the phloem (Fig $3 b)$. Leaf water potential decreases slightly faster than the transpiration rate increases due to gradual loss of xylem hydraulic conductance due to cavitation (Fig. 3a). Phloem conductance decreases with increasing sugar concentration due to decreased phloem sap viscosity (Fig. 3b). An increasing stomatal conductance leads to a decreasing water potential in the xylem, including the sink, while the maximum sink turgor pressure and osmotic concentration are found at an intermediate stomatal conductance (Fig. 3c). The maximum photosynthesis rate, phloem transport rate, and sink sugar utilization rates are found at exactly the same intermediate value of stomatal conductance where the product of internal $\mathrm{CO}_{2}$ concentration and $\phi$ (for photosynthesis), sugar concentration, turgor pressure gradient and phloem conductance (for phloem transport) and sink turgor pressure (for sink sugar utilization) are at their maximum. This value of stomatal conductance where the metabolic rate is maximized is then searched iteratively in the numerical simulations that follow. No solution to Equations 6 and 7 can be found for very large stomatal conductances (larger than shown in Fig 3) due to the fact that there is an upper limit to xylem transport capacity due to run-away cavitation (e.g. Tyree and Sperry, 1988; Hölttä and Nikinmaa, 2013).

Fig. 4 demonstrates photosynthesis rate as a function of leaf internal $\mathrm{CO}_{2}$ concentration $C_{i}$ when the ambient $\mathrm{CO}_{2}$ concentration is constant. Starting from point $a$, stomatal opening increases $C_{i}$ and movement along the $A-C_{i}$ curve where $\phi=1$ to the upper right diagonal direction. But at the same time, stomatal opening causes $\phi$ to decrease as sugar concentration increases to a new steady state value between photosynthesis and phloem transport thus forcing a movement from the $\phi=1$ curve to a lower $A-C_{i}$ curve $(\phi=0.8$ in this case), i.e. towards increased non-stomatal limitations, to point $b$. They key feature here is that movement along a given $A-C_{i}$ curve is associated with a simultaneous movement down to a lower $A-C_{i}$ curve due to increasing non-stomatal limitation. In this case, the movement from $a$ to $b$ due to stomatal opening is desirable as point $b$ has a higher photosynthesis rate $(A)$ than $a$. A further opening of the stomata would take from point $b$ to point $c$, but this would lower the photosynthesis rate and thus no further opening of the stomata is predicted to occur. The increase in photosynthesis rate for a given increase in $C_{i}$ along one $A-C_{i}$ curve increases with a high photosynthetic capacity ( $\alpha$ in Equation (4)) and high light ( $I$ in Equation 4$)$, whereas the decrease to a lower $A-C_{i}$ curve is more drastic with e.g. a high VPD, low xylem and phloem conductance, soil water status and sink strength, and with a low $C_{o}$, i.e. increasing sensitivity of non-stomatal limitations to photosynthesis.

The value of stomatal conductance which maximizes the sustainable metabolic rate (i.e. the simultaneous photosynthesis, phloem transport and sink sugar utilization rate) is dependent on environmental conditions as well as on structural and functional parameters (Figure 5a). The well-known trends of increasing stomatal conductance with increasing PAR and soil water potential (and saturation at high PAR and soil water potential) were captured by the model (Fig 5a). Stomatal conductance was predicted to decrease with increasing VPD ( $g \alpha$ $\left.d_{w}{ }^{-0.50}, \mathrm{R}^{2}=0.99\right)$ and ambient $\mathrm{CO}_{2}$ concentration $\left(g \alpha C_{a}{ }^{-0.58}, \mathrm{R}^{2}=0.94\right.$ and $g \alpha C_{a}{ }^{-0.84} \mathrm{R}^{2}=$ 0.998 when $C_{a}>400 \mathrm{ppm}$ ) (Fig 5a). Stomatal conductance increased with increasing xylem and phloem hydraulic conductance, and with decreasing $\psi_{\text {PLC50 }}$ and leaf area $\left(g \alpha A_{\text {leaf }}^{-0.73}\right.$, $\mathrm{R}^{2}=0.99$ ) (fig $5 \mathrm{~b}$ ). The predicted stomatal conductance was proportional to the square root of xylem hydraulic conductance $\left(g \alpha K_{x}^{0.50}, \mathrm{R}^{2}=0.99\right)$, but it had an almost on-off type relation to 
phloem conductance and $\psi_{\text {PLC50, }}$ with very sharp impact with low conductivity and $\psi_{\text {PLC50 }}$ values followed with almost no impact with further increase in conductivity and $\psi_{\text {PLC50. }}$ started to decrease with very high values of $C_{0}$ (due to sink limitation).

Stomatal conductance increased along with increasing photosynthesis rate in all cases, expect with increasing $C_{a}$ (see Fig. S4a and b in comparison to Fig. 5). This is in line with earlier empirical stomatal conductance models (e.g. Ball et al., 1987; Medlyn et al., 2011). Nonstomatal limitations to photosynthesis generally tended to increase (decreasing $\phi$ ) along with decreasing stomatal conductance with the most notable exceptions being with respect to light and PLC50 (see Fig. S4c and d in comparison to Fig. 5). The relative changes in $\phi$ were smaller than changes in stomatal conductance in all cases (not shown). When the nonstomatal limitations to photosynthesis were made to increase with decreasing leaf water potential (instead of increasing leaf sugar content), the results remained qualitatively similar (see Supplementary Materials Fig. S5). In this case stomatal conductance and the metabolic rate were constrained (although not to the same extent as in Fig. 5) at low phloem conductance and low sink strength by limits of phloem transport to increasing viscosity with increasing phloem sugar concentration (not shown).

Model behaviour was more complex when source strength parameters ( $V_{c m a x}$ and $J_{\max }$ in Equations 3 and 4) and sink strength parameter $\alpha_{\text {sink }}$ in Equations 10 were varied simultaneously (Fig. 6). An increasing sink (Fig. 6a) or source (Fig. 6b) strength increased the stomatal conductance up to a certain point, after which it plateaued. The increase in stomatal conductance with increasing sink or source strength was more pronounced when accompanied with a high source or sink strength, respectively. The maximum sustainable metabolic rate (photosynthesis rate, phloem transport rate and sink unloading rate) increased more with increasing sink strength when source rate was higher (Fig. 6c) and increasing source strength when sink strength was higher (Fig. 6d). A lower sink strength was always accompanied by a higher leaf sugar concentration (Fig. 6e) as higher sugar concentrations in the sink were required for a given sink sugar utilization rate, and this was transmitted as an increased sugar concentration to the source. The effect of source strength on sugar concentration was the opposite; low source strength decreased the sugar concentration as the phloem transport need decreased (Fig. 6f).

Next we compared our solution for the stomatal conductance which maximized steady-state photosynthesis rate to the solution given by the unified stomatal control (e.g. Medlyn et al., 2011), i.e.,

$g=g_{0}+g_{1} \frac{A}{\sqrt{d_{w}} C_{a}}$

where $\mathrm{g}_{0}$ and $\mathrm{g}_{1}$ are parameters. Ambient $\mathrm{CO}_{2}$ concentration $\left(C_{a}\right)$, light intensity $(I)$ and VPD $\left(d_{w}\right)$ were given as input to the model, and their values were varied three-fold (both ways) around their base case values simultaneously in the sensitivity analysis. Further, we varied soil-to-leaf hydraulic conductance $K_{t o t}\left(K_{x}\right.$ and $K_{\text {soil }}$ in same proportion) in our simulations to see how the slope of the stomatal conductance in the unified stomatal control $\left(g_{l}\right)$ model would change. Since the unified stomatal control model uses photosynthesis rate as a predictor for stomatal conductance, a single solution for the optimal stomatal conductance cannot be obtained solely from environmental, structural and physiological parameters. 
Therefore, we used the assimilation rate predicted by our model as an input $A$ to the unified stomatal control model. Our model predictions agreed quite well with the prediction of the unified stomatal control model, i.e. the prediction that there should be a linear relationship between $g$ and $A /\left(\operatorname{sqrt}\left(d_{w}\right) * \mathrm{C}_{a}\right.$ ) (Fig. 7, black points $\left.\mathrm{R}^{2}=0.97\right)$. When we further varied $K_{t o t}$ our results continued to agree with predictions by unified stomatal control model while the slope $g_{l}$ changed (Fig. 7). The slope $g_{l}$ increased approximately in proportion to the square root of soil-to-leaf hydraulic conductance (not shown). Also changes in other structural and functional properties affected the slope (such as $\alpha_{\operatorname{sink}}, C_{0}$ ), but to a much lesser extent, and not so clearly as the soil-to-leaf hydraulic conductance (not shown) as their effect on the predicted stomatal conductance was mediated mainly through changes in $A$, whereas changes in $K_{t o t}$ affected both $A$ and the slope $g_{l}$.

Finally, we compared our numerical solution to the solution given by the optimal stomatal control model (Hari et al., 1986)

$$
g=\left(\sqrt{\frac{C_{a}}{\lambda d_{w}}}-1\right) f \approx \sqrt{\frac{C_{a}}{\lambda d_{w}}} f=\sqrt{\frac{C_{a}}{\lambda d_{w}}} \frac{d}{I+\beta}
$$

where $\lambda$ is the "marginal cost of water" (which was chosen to be so that the stomatal conductance would get similar values in absolute terms), and $\alpha$ and $\beta$ are the light response parameters of photosynthesis, which were given values of $0.1 \mathrm{~mol} \mathrm{~m}^{-2} \mathrm{~s}^{-1}$ and $400 \mu \mathrm{mol} \mathrm{m} \mathrm{s}^{-2}$, respectively (Hari et al., 1986). These values were chosen so that the photosynthetic lightresponse would be similar to the Farquhar model parameterization in our model. Now VPD $\left(d_{w}\right)$ and light $(I)$ were varied three-fold (both ways) around their base case values simultaneously, while $C_{a}$ was kept constant as the optimal stomatal model gives contradictory $C_{a}$ responses (assuming constant $\lambda$ ). Again, the predictions of the two models coincided (Fig 8a black points, $\mathrm{R}^{2}=0.87$ ), although the scatter was higher and there was more non-linearity in comparison to the unified stomatal control model. This may be due to the fact the optimal stomatal conductance model uses a different form of the photosynthesis function (see e.g. Hari et al., 1986). The slope, i.e. $1 / \operatorname{sqrt}(\lambda)$, increased again approximately in proportion to $K_{t o t}$ (not shown). Now also changes in other structural and functional parameters affected the slope; e.g. the slope increased with increasing sink strength $\left(\alpha_{\text {sink }}\right)$ and $C_{0}$ (see Supplementary Materials Fig. S6). When the changes in non-stomatal limitations to photosynthesis were added to optimal stomatal conductance so that the solution for stomatal conductance in the above equation was multiplied by $\phi$, the agreement between the models increased significantly (Fig. $8 \mathrm{~b}, \mathrm{R}^{2}=0.98$ for the base case parameterization, black points). Overall, our results imply that the square root of the marginal water cost of carbon gain $(\lambda)$ in the optimal stomatal conductance model and $g_{l}$ in the unified stomatal control model are linearly proportional to soil-to-leaf hydraulic conductance, i.e. stomatal conductance is proportional to the square soil-to-leaf hydraulic conductance. This is in line with the interpretation that $g_{1}$ is proportional to the square root of the marginal water cost of carbon gain $(\lambda)$ (Medlyn et al., (2011). Note that the $\lambda$ in equation above after Hari et al. (1986) and Mäkelä et al. (1996) is the inverse of $\lambda$ in the formulation by Cowan and Farquhar (1977) and Medlyn et al. (2011). In both model comparisons, changes in VPD $\left(d_{w}\right)$ and soil-to-leaf hydraulic conductance $\left(K_{t o t}\right)$ affect the predicted stomatal conductance exactly in the opposite manner, as their effect on leaf water potential is the opposite, i.e. $\psi_{\text {leaf }} \alpha K_{t o t} / d_{w}$. 
Carbon assimilating leaves and carbon sinks are connected to each other through xylem and phloem so a key task of stomatal regulation is to match leaf gas exchange to the internal circulation of sap in trees. When water potential or sugar concentration of one tissue within a tree changes, xylem and phloem propagate this change to other tissues (Pantin et al., 2012, Nikinmaa et al., 2013). Since the rate of source and sink processes are dependent on water and carbohydrate status, changes in sink status will be reflected to source status and vice versa. Our numerical analysis utilizing this theoretical framework demonstrates that the previously well-known responses of stomatal behaviour are in good agreement with maximizing the photosynthesis rate in steady state when the above source-sink connection and tree hydraulics are considered (Figs. 5 and 6). The results from our numerical solution are very similar to the results from the widely applicable unified stomatal conductance model (Medlyn et al., 2011; Lin et al., 2015) (Fig. 7), and thus also very similar to the solutions by Ball et al. (1987) and Leuning (1995). In addition, our model makes stomatal behavior directly responsive to drought conditions and cases of sink limitation. Our model provides a potential explanation for the marginal water cost in the unified stomatal conductance model and optimal stomatal model, which until now have been estimated through empirical parameter fitting and been found to vary e.g. between plant functional types and in different environments (e.g. Mäkelä et al., 1996; Kolari et al., 2007; Prentice et al.. 2014; Lin et al., 2015).

In our model simulations the stomatal and non-stomatal limitations to photosynthesis are tightly coupled (Fig. 8). In essence, our prediction is similar also in this aspect to the prediction by the models of Ball et al. (1987), Leuning (1995) and Medlyn et al. (2011) since in these models stomatal conductance is proportional to photosynthesis rate. The wide usability of these models would suggest that such linking is frequent in trees. In our approach, the linking arises since assuming the feedback between the rate of photosynthesis and photosynthate accumulation allows us to find a stomatal conductance that balances gas exchange with sap circulation at a maximum possible photosynthetic rate. It has been evident for a long time that, at least at the longer time scale, for example during the progression of a drought, stomatal and non-stomatal limitations to photosynthesis are coordinated with each other (e.g. Flexas and Medrano, 2002; Zhou et al., 2014; Manzoni, 2014). In addition, recent reviews have highlighted the dynamic nature of mesophyll conductance; mesophyll conductance can change as fast as stomatal conductance, i.e. within seconds or minutes (Flexas et al., 2008 and 2012, Kaiser et al., 2015) and regardless of how fast the environmental conditions change (Flexas et al., 2012). Typically mesophyll conductance has been found to change in parallel with stomatal conductance (Flexas et al., 2008), and midday depression of photosynthesis has been attributed to both stomatal and non-stomatal limitations to photosynthesis, even during non-drought conditions (e.g. Zhang and Gao, 2000; Nascimento and Marenco, 2013; Mediavilla et al., 2002). The reasons for changes in mesophyll conductance are not well understood, but factors that may contribute to variations in it are e.g. changes in carbonic anhydrase, aquaporin activity, and the area of chloroplasts facing intercellular spaces (Kaiser et al., 2015). We further hypothesize that one additional purely physical candidate for affecting mesophyll conductance could be the decrease in the aqueous phase diffusion coefficient for $\mathrm{CO}_{2}$ with increasing sugar concentration (e.g. Carrol et al., 2014).

Most of the studies have linked increases in non-stomatal limitations to photosynthesis to water stress, but also increasing sugar and starch concentration in leaves have been found to 
decrease photosynthetic production (e.g. Nafziger and Koller 1976; Iglesias et al., 2001; 347 Goldschmidt and Huber, 1992; Myers et al., 1999). More specifically, increasing leaf sugar concentrations have been found to increase non-stomatal limitations to photosynthesis (Turnbull et al., 2002; Hüve et al., 2006; Frank et al., 2006; Quentin et al., 2013; Kitao et al., 2015). However, the functional form of the relation between the decrease in $A$ for a given $C_{i}$ and light with increasing leaf sugar concentration has not been quantitatively and extensively tested (but see e.g. Franck et al., 2006 and our experimental results in Fig. 2). In general, it might be difficult to distinguish between the effects of leaf water potential vs. sugar concentration on photosynthesis since these two are so intimately linked to each other unless sink strength is changing or active osmoregulation is occurring.

Our modelling results also demonstrate (Fig. 8) that the changes in non-stomatal limitations need not be extremely large since the concurrent decrease in stomatal conductance will prevent the non-stomatal limitations from decreasing excessively. Our analysis thus highlights the need for more studies on the nature of the non-stomatal limitations to photosynthesis and how they respond to changes in leaf water and sugar status. In any case, our results show that formulation such a feedback allows linking stomatal conductance with whole tree level water and source-sink relationships and provides very realistic stomatal behaviour. If this feedback is excluded from the model, then the maximum steady-state photosynthesis rate would only be limited by transport capacity of the xylem and phloem (Hölttä and Nikinmaa, 2013) and feasible outcome would include unrealistically high leaf sugar concentrations with a tendency for irregular stomatal behaviour, unless other concepts, such as the cost of water are introduced to the model formulation.

Our analysis predicts that photosynthesis is simultaneously source and sink-limited (Fig. 6). When source strength is very high then sink strength will start to affect photosynthetic production and vice versa. In the model results increasing source strength above a given threshold does not increase photosynthesis rate without a simultaneous increase in sink strength and vice versa (Fig. 6). High source strength and low sink strength are predicted to increase osmotic concentration and turgor pressure at the sink. In the case that photosynthesis is source limited while sink strength is very high, sugar concentration is predicted to change hand in hand with water potential, but in the case of sink limitation, leaf sugar concentration is predicted to increase much faster than leaf water potential decreases (i.e. turgor pressure increases). If sink strength decreases, then the osmotic concentration and turgor pressure at the sink have to increase even more than sink water potential decreases to maintain a constant rate of sink sugar consumption. This is reflected to the source through the phloem as an increase in both osmotic concentration and turgor pressure. Turgor pressure and osmotic concentration have to be raised even more in source in comparison to the sink in case phloem transport capacity is decreased. A high turgor pressure in the leaf is thus predicted to reflect sink limitation and a low turgor pressure source limitation (Patrick, 2013). If the high leaf turgor pressure is accompanied with high sink turgor pressure, then the sink limitation is caused by insufficient sink strength. If not, then the sink limitation is caused by low phloem transport capacity. Note that by sink limitation we here mean that the rate of sugar utilization for a given sugar concentration or turgor pressure is low, i.e. we do not distinguish whether the sugars are utilized in growth, respiration, storage, soil exudation or some other processes.

The major limitations of our model are that 1) it is a steady state model in which 2) sucrose is assumed to be the only osmotic component. The steady state assumption does not allow for buffering of short time scale imbalances between photosynthetic production rate, phloem transport rate and sink sugar utilization rate by e.g. starch dynamics or elastic changes in 
tissue volume; this would require the use of a dynamic model. A dynamic analysis is very challenging since each of the processes involved in the theoretical framework can reach a steady state at different time scales ranging from less than seconds for the light reactions of photosynthesis (Porcar-Castell et al., 2014) to hours or days for the phloem sugar concentration (Thompson and Holbrook 2003). The stomatal conductance that maximizes a metabolic rate would thus depend on the time scale on which that optimization problem is done on (Nikinmaa et al., 2013). However, it is possible that stomatal responses could anticipate future equilibrium states (Pantin et al., 2012; Nikinmaa et al., 2013). In fact, stomatal closure and increases in non-stomatal limitations to photosynthesis in response to a decrease in sink strength have been found to occur before noticeable accumulation of sugar and starch in the leaves (Nebauer et al., 2011). Trees are hierarchical structures and most likely leaves are in steady-state to proximal woody axes that changes dynamically as the more distal parts react to e.g. soil moisture changes. The big difference between the pressure propagation due to hydrostatic vs. osmotic reasons causes an interesting further aspect to whole tree level response dynamics. While the transpiration driven pressure changes propagate through a large tree in minutes, changes in sugar concentration may take days). Against that background, the assumption of sucrose being the only osmotically active substance links the sugar concentration dependence of both photosynthesis and sink sugar consumption to osmotic regulation too strongly. It does not take into account that smaller molecular mass sugars, such as glucose and fructose (e.g. Woodruff, 2014), or other solutes, such as potassium, could produce a higher ratio of osmotic concentration to phloem sap viscosity with also an impact on the tree level response dynamics.

A major advantage of our approach is that it links source-sink reactions through xylem and phloem transport, offering a way to understand their mutual interactions within a tree. Our results suggest that there are thresholds of phloem conductivity and xylem vulnerability to cavitation that cause stomata to close (Fig. 5b). Runaway cavitation has been long identified as a critical boundary condition for stomatal opening (Tyree and Sperry, 1988). The predicted response of stomatal conductance to $\psi_{\mathrm{PLC}} 50$ and phloem conductivity are highly non-linear; excess resistance to cavitation or phloem transport capacity beyond a certain level brings only marginal benefit. A very vulnerable xylem causes leaf water potential to decrease quickly. Similarly, a very low phloem conductance causes sugars to build up in the leaves, increasing the non-stomatal limitation to photosynthesis. Above a threshold phloem conductance, sink activity limits phloem transport. One would thus expect the phloem conductance of trees to be linked to the maximum attainable photosynthetic rate, in the same way as the $\psi_{\text {PLC50 value }}$ is related to the minimum water potential a tree is likely to experience (Choat et al., 2012). It seems unlikely that trees would build extra phloem transport capacity due to its high nitrogen costs (Hölttä et al., 2013). In contrast to phloem conductance, increasing the xylem conductance increased the predicted stomatal conductance (Fig. 5b). Also some previous studies indicate that xylem conductance increases faster than phloem conductance as trees grow in size (Hölttä et al., 2013). However, xylem conductance is coupled with xylem vulnerability to cavitation as both depend on the pit membrane characteristics (Cochard, 2006), complicating the relationship between xylem conductance and optimum stomatal conductance. It is therefore possible that the minimum vulnerability to cavitation may impose a maximum level of xylem conductivity (Gleason et al., 2016).

The present approach does not suggest a physiological mechanism for stomatal regulation but shows plant level implications of leaf gas exchange that reproduce observed features when carbon uptake is maximized. The key dynamic feature that reflects the processes in the different parts of plant is the sugar concentration in leaves. Recently, it has been suggested 
that sucrose mediated by hexokinases and ABA could directly induce closing of guard cells (Kelly et al., 2013). This, together with the feedbacks from sugar sensing pathways to photosynthetic rate (Granot et al., 2013) could represent the mechanisms that generate the predicted behaviour. In any case, our approach shows a framework of physiologically quantifiable processes that produce in concert the known features of stomatal behaviour.

\section{Materials and methods}

\section{Interactions between source, transport and sink}

The interconnections and the underlying mathematical formulation used amongst transpiration, photosynthesis, xylem and phloem transport, soil water status, and sink sugar status are depicted in Fig. 1. The driving forces of water vapour and $\mathrm{CO}_{2}$ exchange with the atmosphere through the stomata are the difference in their concentrations between the ambient air and leaf internal space. The utilization of $\mathrm{CO}_{2}$ in photosynthesis creates and maintains the difference in the $\mathrm{CO}_{2}$ concentration required for $\mathrm{CO}_{2}$ inflow. The sugars assimilated by photosynthesis are passed passively along the concentration gradient in trees (Turgeon, 2010) from the mesophyll cells to the phloem. The assimilated sugars draw water osmotically to the leaf phloem from the adjacent xylem tissue to maintain water potential equilibrium and simultaneously increase phloem hydrostatic (turgor) pressure. This positive pressure in the leaf phloem pushes water and dissolved sugars in the direction of the pressure gradient towards locations where the sugars are used in carbon sinks. Sugar utilization in the sink lowers the sink osmotic concentration, and also the turgor pressure as water potential equilibrium between the xylem and phloem is maintained at all locations in the tree. In the absence of sufficient sugar utilization in the sink, sugar concentration increases in the phloem and also in the leaves.

An important aspect is that all of the processes described in Fig. 1 are coupled to each other and constrained by one another. A change in one variable, e.g. pressure, concentration, resistance or enzymatic rate constant (e.g. $V_{\text {cmax }}$ in leaf or $\alpha_{\text {sink }}$ in sink), at one location will induce changes in pressure and concentration at all other locations within the plant. In steady state, the transpiration rate $(E)$ must equal xylem sap flow rate $\left(J_{x}\right)$ and rate of water uptake from the soil. $\mathrm{CO}_{2}$ assimilation rate $(A)$ must equal the phloem sap flow rate $\left(J_{p}\right)$, which in turn must equal the rate of sugar utilization at sink. Xylem and phloem are tightly hydraulically coupled (e.g. Pfautsch et al., 2015; Steppe et al., 2015) so that phloem turgor pressure plus osmotic pressure must equal xylem water potential in all parts of the tree. Xylem conductance $\left(k_{x}\right)$ is dependent on xylem water potential due to embolism formation by cavitation, and phloem conductance is dependent on sugar concentration due to viscosity. Transpiration, soil water availability, photosynthesis and sugar utilization at the sinks, and the conductances for diffusion and mass flow, set the gradients for xylem and phloem transport.

\section{Model Description}

\section{Leaf gas exchange}

The driving force for stomatal gas exchange of $\mathrm{CO}_{2}$ is the difference between the $\mathrm{CO}_{2}$ concentration in ambient air $\left(C_{a}\right.$, molar fraction of $\mathrm{CO}_{2}$ in ambient air) and $\mathrm{CO}_{2}$ concentration in the intercellular air spaces inside the leaves $\left(C_{i}\right.$, molar fraction of $\mathrm{CO}_{2}$ in the intercellular air spaces). The (leaf-area specific) rate of $\mathrm{CO}_{2}$ diffusion $\left(D_{\mathrm{CO} 2}, \mathrm{~mol} \mathrm{~m} \mathrm{~m}^{-2} \mathrm{~s}^{-1}\right)$ to the leaf internal space is 
where $g$ is stomatal conductance $\left(\mathrm{mol} \mathrm{m} \mathrm{m}^{-2} \mathrm{~s}^{-1}\right)$. Similarly for water, the rate of (leaf-area specific) water vapor diffusion to the air $\left(E, \mathrm{~m}^{3} \mathrm{~m}^{-2} \mathrm{~s}^{-1}\right)$ is

where $W_{i}$ and $W_{a}$ are the intercellular and ambient molar fractions of water vapor $\left(\mathrm{mol}_{\mathrm{H} 20} / \mathrm{mol}_{\mathrm{air}}\right), F_{\text {mol-m3 }}$ is a factor $\left(18^{*} 10^{-6} \mathrm{~m}^{3} \mathrm{~mol}^{-1}\right)$ for converting the units of transpiration rate from molm $^{-2} \mathrm{~s}^{-1}$ to $\mathrm{m}^{3} \mathrm{~m}^{-2} \mathrm{~s}^{-1}$ to match the units of xylem water transport rate (Equation 6) and $d_{w}$ is vapor pressure deficit (VPD, $\mathrm{mol}_{\mathrm{H} 20} / \mathrm{mol}_{\text {air }}$ ). The factor 1.6 in Equation (2) arises as stomatal conductance is expressed for $\mathrm{CO}_{2}$, and the corresponding value for water is 1.6 times larger.

At steady state, the rate of $\mathrm{CO}_{2}$ consumption in photosynthesis in the chloroplasts $(A)$ must be the same as the rate of diffusion from the ambient air $\left(D_{\mathrm{CO} 2}\right)$. Photosynthesis was modelled

$A=\min \left(V_{c \max } \frac{C_{i}-\Gamma}{C_{i}+K_{c}\left(1+O / K_{0}\right)}, J \frac{C_{i}-\Gamma}{4 C_{i}+8 \Gamma}\right)$

where

$519 \quad J=\frac{q I+J_{\max }-\sqrt{\left(q I+J_{\max }\right)^{2}-4 \Theta q I J_{\max }}}{2 \Theta}$

and $V_{c \max }, J, J_{\max }, \Gamma, K_{c}, O, K_{o}, q, \Theta$ are parameters of the Farquhar photosynthesis model (see Table 1), and $I$ is light intensity.

The photosynthetic parameters $V_{\text {cmax }}$ and $J$ were made to be dependent on leaf sugar concentration to account for the changes in the non-stomatal limitations to photosynthesis. The changes in the non-stomatal limitations to photosynthesis were modelled by multiplying the maximum values of $V_{c \max }$ and $J, V_{c \max , O}$ and $J_{0}$, respectively, by a unit less factor $\phi(\phi \leq 1)$.

and

$J=\phi J_{0}$

Because the functional form for the relationship between the changes in the non-stomatal limitations to photosynthesis and leaf sugar concentration is not known, we applied a linear relationship between them 
$\phi=1-\frac{C_{\text {leaf }}}{C_{0}}$

if $\mathrm{C}_{\text {leaf }}<\mathrm{C}_{\mathrm{o}} \quad\left(\phi=0\right.$ if $\left.\mathrm{C}_{\text {leaf }}>\mathrm{C}_{\mathrm{o}}\right)$

540

541

542

543

544

545

546

547

548

549

550

551

552

553

554

555

556

557

558

559

560

561

562

563

564

565

566

567

568

569

570

571

572

573

574

575

576

579

580

581

582 where $C_{0}$ is the sugar concentration at which photosynthesis vanishes. A similar function of linearly increasing non-stomatal limitations to photosynthesis with increasing leaf sugar concentration was used in the models of Nikinmaa et al. (2013) and Mencuccini et al. (2015) and is also supported by the measurements in this study (see Fig. 1). Changes in $V_{c \max }$ and $J$ were here conducted simultaneously as they typically vary in concert (Wullschleger, 1993; Meir et al., 2002). Also Zhou et al. (2013) found that whether the non-stomatal limitations to photosynthesis are included in the $V_{c \max }$ or $J_{\max }$ term makes a little difference to the final result. Leaf respiration was not included in the model formulation. Photosynthesis rate was modelled as a function of leaf internal $\mathrm{CO}_{2}$ concentration $\left(C_{i}\right)$, instead of $\mathrm{CO}_{2}$ concentration in chloroplasts. This way the changes in $V_{c m a x}$ and $J_{0}$ implicitly include the changes in both mesophyll conductance and in the biochemistry of photochemistry, i.e. changes in e.g. RuBP utilization and regeneration.

Non-stomatal limitations to photosynthesis have been quantified as a function of both leaf sugar content $\left(C_{\text {leaf }}\right)$ e.g. in Turnbull et al. (2002) and Frank et al. (2006) and leaf water otential (e.g. Kellomäki and Wang 1996; Zhou et al., 2014). Modelling the non-stomatal limitations as a function of leaf water potential would lead to a very similar outcome except in the situation where sink strength changes since leaf water potential and osmotic concentration are in other cases very well coupled. The formulation used, i.e. the sugar concentration dependence, allows us to capture the effects of both water stress and decreased sink sugar utilization rate on photosynthesis and stomatal conductance.

Since the relation between leaf sugar concentration and the non-stomatal limitations to photosynthesis turn out to be important relations affecting the model behavior and so few quantitative description on this relation can be found in the literature, we performed laboratory measurements to approximately quantify this relation for Scots pine seedlings (see Laboratory measurements section).

\section{Xylem and phloem transport}

Leaf area-specific water flux from the root to the leaf $\left(J_{x}\right)$ is described as a function of the leaf area-specific xylem hydraulic conductance $\left(K_{x}, \mathrm{mPa}^{-1} \mathrm{~s}^{-1}\right)$, which decreases with decreasing water potential due to cavitation according to a Pammenter type vulnerability curve (Pammenter and Willingen, 1998), and the water potential difference between the root $\left(\psi_{\text {root }}\right)$ and leaf $\left(\psi_{\text {leaf }}\right)$

$J_{x}=K_{x}\left(\psi_{\text {root }}-\psi_{\text {leaf }}\right)=K_{x, 0}\left(1-\exp \left(a_{x y l e m}\left(\psi_{\text {leaf }}-\psi_{P L C 50}\right)\right)-1\right)\left(\psi_{\text {root }}-\begin{array}{r}577 \\ y_{578}\end{array}\right)$

where $a_{x y l e m}$ is the slope of the vulnerability curve and $\psi_{P L C 50}$ is the water potential where half of the initial hydraulic conductance of the xylem $K_{x, 0}$ has been lost due to cavitation. Water flow rate from the soil to root is the same as the water flow rate in the xylem

$J_{\text {soil }}=K_{\text {soil }}\left(\psi_{\text {soil }}-\psi_{\text {root }}\right)=K_{\text {soil }, \text { sat }}\left(\psi_{e} / \psi_{\text {soil }}\right)^{a_{\text {soil }}}\left(\psi_{\text {soil }}-\psi_{585^{t}}^{584}\right)$ 
601

\section{5}

606

607

608

609

610

611

612

613

$$
U=\frac{\alpha_{\sin k} C_{6145}^{614}}{C_{\sin k}+6161_{s} k}
$$$$
617
$$

where $K_{p}$ is phloem hydraulic conductance (which is dependent on temperature and sugar concentration due to its viscosity dependence), $P_{\text {leaf }}$ and $P_{\text {root }}$ are the turgor pressures in the leaf and root, and $\eta\left(C_{\text {leaf }}\right)$ is viscosity (in relation to pure water).

Xylem and phloem water potential $(\psi)$ are at equilibrium both in the leaves (source) and roots (sink).

$$
\begin{array}{r}
\psi=P-60 B B \\
604
\end{array}
$$

where $C$ and $P$ are the sugar concentration and turgor pressure (either leaf or sink phloem), $R$ is the molar gas constant and $T$ is temperature $(\mathrm{K})$.

\section{Sugar utilization in sinks}

Sugar unloading rate, i.e. sugar utilization rate in sinks $(U)$, is described as a function of phloem sugar concentration at the sink with a Michaelis-Menten type function (e.g. Thompson and Holbrook, 2003)

where $\alpha_{\operatorname{sink}}$ and $\beta_{\operatorname{sink}}$ are parameters. In addition, a condition was imposed that turgor pressure has to remain larger than zero at the sink. This condition did not affect the model results except in the case where soil water potential decreased below or sink strength increased above its base case value.

\section{Model runs with numerical model}

As the whole set of coupled Equations (1) to (10) cannot be solved analytically without some assumptions relaxed, we resort to a numerical steady state solution of these equations where the transpiration rate ( $E$ in Equation 2$)$ is set to the xylem transport rate ( $J_{x}$ in Equation 6$)$, and the $\mathrm{CO}_{2}$ assimilation rate $\left(A\right.$ in Equation 1) to phloem transport rate $\left(J_{p}\right.$ in Equation 8$)$ and the rate of sugar utilization in the sinks ( $U$ in Equation 10). The equations were solved iteratively using a self-made algorithm in Fortran 90. Briefly, stomatal conductance is changed from zero to its maximum value of $0.1 \mathrm{~mol} \mathrm{~m}^{-2} \mathrm{~s}^{-1}$. For each stomatal conductance and environmental driving variables one combination of photosynthesis rate, transpiration rate, xylem water potential at source and sink, phloem pressure and concentrations at source and sink is found where the system is in steady state. There is only one source and sink in the model, which represent the leaves and roots, respectively (see Fig. 1a). The algorithm then chooses the stomatal conductance which yields the highest photosynthesis rate. 
638 In the results section we first demonstrate model behaviour in terms of varying stomatal conductance with a standard set of parameters and environmental driving variables (Table 1). photosynthesis, phloem transport and sink sugar utilization rate as a function of environmental conditions and structural parameters, i.e. use the model to predict the optimal stomatal conductance when each of the environmental conditions and structural parameters are varied at a time. Next, we find the numerical optimal solution for stomatal conductance when VPD, ambient $\mathrm{CO}_{2}$ concentration and tree structural and functional properties are varied together, and compare this to the analytical solution of stomatal conductance given by the unified stomatal conductance model (e.g. Medlyn et al., 2011), which has been tested in field conditions at numerous sites (e.g. Lin et al., 2015), and optimal stomatal control model (Hari et al., 1986)

\section{Laboratory measurements}

We performed experiments on Scots pine (Pinus sylvestris L.) seedlings in the laboratory to quantify the relationship between leaf osmotic concentration and non-stomatal limitation to photosynthesis expressed in Equation 5. The seedlings of approximately 1 meter in height and $2 \mathrm{~cm}$ diameter at base were brought inside the lab approximately one week before the measurements and were well watered. During the experiment, they were kept in constant environmental conditions (PAR $\sim 400 \mu \mathrm{mol} \mathrm{m} \mathrm{s}^{-1}$, VPD $\sim 0.01 \mathrm{~mol} \mathrm{~mol}^{-1}$, ambient $\mathrm{CO}_{2}$ concentration $\sim 450 \mathrm{ppm}$, temperature $\sim 22{ }^{\circ} \mathrm{C}$ ) for 3 to 8 hours. The needles inside the cuvette were kept in the same environmental conditions as the other needles. After a stabilisation period of approximately one hour, some of the seedlings $(n=3)$ were girdled and some were notched $(n=4)$ on the branch, approximately $20 \mathrm{~cm}$ from the point of measurement of leaf gas exchange, while some seedlings were kept intact $(n=3)$. Girdling and notching treatments were used to make the water and osmotic potentials and leaf gas exchange to vary as much as possible. Notching was done by incising the xylem in one location with a razor blade in order to decrease xylem hydraulic conductance and thus leaf water potential (Sperry et al. 1993). Girdling was done to prevent phloem transport below the girdle to increase leaf sugar concentration and cause sink limitation without a decrease in leaf water potential. During the experiments, leaf gas exchange (water and $\mathrm{CO}_{2}$ ) was measured with a flowthrough gas exchange measurement system (GFS-3000, Walz, Germany), leaf osmotic concentration was measured with a freezing point osmometer (Osmomat-030, Gonotec, Berlin, DE) and water potential was measured with a PMS pressure chamber. Note that the osmometer actually measures osmolality (units: $\mathrm{mol} \mathrm{kg}^{-1}$ ), but we approximate this to be the same as osmotic concentration (units: mol $^{-1}$ ) since these two are very close to each other in dilute solutions such as ours. Needles for the osmotic concentration and water potential measurements were collected close to the point of leaf gas exchange measurements. For the osmotic concentration measurements 3 to 5 pairs of needles were first sealed in set in silicabased membrane collection tubes (GeneJET Plasmid Miniprep Kit, Thermo Scientific, Massachusetts, USA) and then dipped in liquid nitrogen and stored at $-80{ }^{\circ} \mathrm{C}$. Within a week, they were thawed and centrifuged at $14000 \mathrm{~g}$ for $10 \mathrm{~min}$ (Heraeus Fresco 17, Thermo Scientific, Massachusetts, USA). The resulting sap obtained was measured with the osmometer without delay. Measurements were conducted in May and June in 2015 in the laboratory at the Department of Forest Sciences in Helsinki University. The gross photosynthesis rate $(A)$ was calculated by adding the respiration rate to the net $\mathrm{CO}_{2}$ assimilation rate (assumed constant as temperature was kept constant) from the net leaf $\mathrm{CO}_{2}$ exchange rate. Respiration rate was measured at the beginning and end of the experiment by 
keeping the seedling in the dark for at least 15 minutes. Since the light and ambient $\mathrm{CO}_{2}$ levels were kept constant and the variation in $C_{i}$ was so small in our experiments, changes in non-stomatal limitations to photosynthesis ( $\phi$ in Equation 5), were calculated from the $A$ to $C_{i}$ ratio (see Supplementary Materials Figs. S1 and S2).

\section{Acknowledgements}

Funding from Academy of Finland projects \#268342 and \#272041.

\section{Author contributions}

TH, EN and AM designed the theory and the model. TH performed the model simulations. $\mathrm{AL}$ and TC conducted the laboratory measurements. All authors participated in writing the manuscript.

\section{References}

Ball JT, Woodrow IE, Berry JA (1987) A model predicting stomatal conductance and its contribution to the control of photosynthesis under different environmental conditions. In Progress in Photosynthesis Research, Vol. IV (ed. I. Biggins), pp. 221-224.

Buckley TN, Diaz-Espejo A (2015) Partitioning changes in photosynthetic rate into contributions from different variables. Plant Cell Environ 38: 1200-1211.

Campbell GS (1974) A simple method for determining unsaturated conductivity from moisture retention data. Soil Science 117: 311-314.

Carroll NJ, Jensen, KH, Parsa S, Holbrook NM, Weitz DA (2014) Measurement of flow velocity and inference of liquid viscosity in a microfluidic channel by fluorescence photobleaching. Langmuir 30: 4868-4874.

Choat B, Jansen S, Brodribb, TJ, Cochard H, Delzon S, Bhaskar R, ..., Zanne AE (2012) Global convergence in the vulnerability of forests to drought. Nature 491: 752-755.

Cochard H (2006) Cavitation in trees. CR Physique 7: 1018-1126.

Cowan IR, Farquhar GD (1977) Stomatal function in relation to leaf metabolism and environment. In: Jennings DH ed. Integration of activity in the higher plant. Cambridge: Cambridge University Press, 471-505.

De Schepper V, Steppe K (2010) Development and verification of a water and sugar transport model using measured stem diameter variations. J Exp Bot 61: 2083-2099.

Duursma RA, Kolari P, Perämäki M, Nikinmaa E, Hari P, Delzon S, ... Mäkelä A (2008) Predicting the decline in daily maximum transpiration rate of two pine stands during drought based on constant minimum leaf water potential and plant hydraulic conductance. Tree Physiol 28: 265-276. 
Farquhar GD, Von Caemmerer S, Berry JA (1980) A biochemical model of photosynthetic CO2 assimilation in leaves of C3 species. Planta 149: 78-90.

Flexas J, Medrano H (2002) Drought-inhibition of photosynthesis in C3 plants: stomatal and non-stomatal limitations revisited. Ann Bot 89: 183-189.

Flexas J, Ribas-Carbo M, Diaz-Espejo A, Galm ES, Medrano H (2008). Mesophyll conductance to $\mathrm{CO} 2$ : current knowledge and future prospects. Plant Cell Environ 31: 602621.

Flexas J, Barbour MM, Brendel O, Cabrera HM, Carriquí M, Díaz-Espejo A, ... Gallé A (2012). Mesophyll diffusion conductance to CO2: an unappreciated central player in photosynthesis. Plant Sci 193: 70-84.

Franck N, Vaast P, Génard M, Dauzat J (2006) Soluble sugars mediate sink feedback down-regulation of leaf photosynthesis in field-grown Coffea arabica. Tree Physiol 26: 517525.

Gago J, de Menezes Daloso D, Figueroa CM, Flexas J, Fernie AR, Nikoloski Z (2016)

Relationships of Leaf Net Photosynthesis, Stomatal Conductance, and Mesophyll Conductance to Primary Metabolism: A Multispecies Meta-Analysis Approach. Plant Physiol 171: $265-279$.

Gleason SM, Westoby M, Jansen S, Choat B, Hacke UG, Pratt RB, ..., Zanne AE (2016). Weak tradeoff between xylem safety and xylem-specific hydraulic efficiency across the world's woody plant species. New Phytol 209: 123-136.

Goldschmidt EE, Huber SC (1992) Regulation of photosynthesis by end-product accumulation in leaves of plants storing starch, sucrose, and hexose sugars. Plant Physiol 99: 1443-1448.

Granot D, David-Schwartz R, Kelly G (2013) Hexose kinases and their role in sugarsensing and plant development. Front Plant Sci 4: 44.

Guo WD, Guo YP, Liu JR, Mattson N (2009). Midday depression of photosynthesis is related with carboxylation efficiency decrease and D1 degradation in bayberry (Myrica rubra) plants. Sci Hort 123: 188-196.

Hari P, Mäkelä A (2003) Annual pattern of photosynthesis in Scots pine in the boreal zone. Tree Physiol 23: 145-155.

Hüve K, Bichele I, Tobias M, Niinemets Ü (2006). Heat sensitivity of photosynthetic electron transport varies during the day due to changes in sugars and osmotic potential. Plant Cell Environ 29: 212-228.

Hölttä T, Mäkinen H, Nöjd P, Mäkelä A, Nikinmaa E (2010) A physiological model of softwood cambial growth. Tree Physiol 30: 1235-1252. 
Hölttä T, Kurppa M, Nikinmaa E (2013) Scaling of xylem and phloem transport capacity Hölttä T, Nikinmaa E (2013, June). Modelling the effect of xylem and phloem transport on leaf gas exchange. In IX International Workshop on Sap Flow 991 pp. 351-358.

Iglesias DJ, Lliso I, Tadeo FR, Talon M (2002) Regulation of photosynthesis through source: sink imbalance in citrus is mediated by carbohydrate content in leaves. Physiol Plant 116: $563-572$.

\section{Kaiser E, Morales A, Harbinson J, Kromdijk J, Heuvelink E, Marcelis LF (2015).}

Dynamic photosynthesis in different environmental conditions. J Exp Bot 66: 2415-2426.

Kellomäki S, Wang KY (1996) Photosynthetic responses to needle water potentials in Scots pine after a four-year exposure to elevated CO2 and temperature. Tree Physiol 16: 765-772.

Kelly G, Moshelion M, David-Schwartz R, Halperin O, Wallach R, Attia Z, Belausov E, Granot D (2013) Hexokinase mediates stomatal closure. Plant J 75: 977-988.

\section{Kitao M, Yazaki K, Kitaoka S, Fukatsu E, Tobita H, Komatsu M, ..., Koike T (2015)} Mesophyll conductance in leaves of Japanese white birch (Betula platyphylla var. japonica) seedlings grown under elevated $\mathrm{CO} 2$ concentration and low $\mathrm{N}$ availability. Physiol Plant 155: 435-445.

Kolari P, Lappalainen HK, Hänninen H, Hari P (2007) Relationship between temperature and the seasonal course of photosynthesis in Scots pine at northern timberline and in southern boreal zone. Tellus 59B: 542-552.

Körner C (2003) Carbon limitation in trees. J Ecol 91: 4-17.

Leuning R (1995) A critical appraisal of a combined stomatal-photosynthesis model for C3 plants. Plant Cell Environ 18: 339-355.

Lin YS, Medlyn BE, Duursma RA, Prentice IC, Wang H, Baig S, ..., da Costa AC L (2015) Optimal stomatal behaviour around the world. Nature Clim Change. 5: 459-464

Manzoni S (2014) Integrating plant hydraulics and gas exchange along the drought-response trait spectrum. Tree Physiol 34: 1031-1034.

McDowell NG, Beerling DJ, Breshears DD, Fisher RA, Raffa KF, Stitt M (2011) The interdependence of mechanisms underlying climate-driven vegetation mortality. Trends Ecol Evolut 2: 523-532.

Mediavilla S, Santiago H, Escudero A (2002) Stomatal and mesophyll limitations to photosynthesis in one evergreen and one deciduous Mediterranean oak species. Photosynthetica 40: 553-559.

Meir P, Kruijt B, Broadmeadow M, Kull O, Carswell F, Nobre A, Jarvis PG (2002) Acclimation of photosynthetic capacity to irradiance in tree canopies in relation to leaf nitrogen concentration and leaf mass per unit area. Plant Cell Environ 25:343-57 

KY, De Angelis P, Freeman M, Wingate L (2011) Reconciling the optimal and empirical approaches to modelling stomatal conductance. Glob Change Biol 17: 2134-2144.

Mencuccini M, Minunno F, Salmon Y, Martínez-Vilalta J, Hölttä T (2015). Coordination of physiological traits involved in drought-induced mortality of woody plants. New Phytol 208: 396-409.

Mäkelä A, Berninger F, Hari P (1996) Optimal control of gas exchange during drought: Theoretical analyses. Ann Bot 77: 461-467.

Myers DA, Thomas RB, DeLucia EH (1999) Photosynthetic responses of loblolly pine (Pinus taeda) needles to experimental reduction in sink demand. Tree Physiol 19: 235-242.

Nafziger ED, Koller HR (1976) Influence of leaf starch concentration on CO2 assimilation in soybean. Plant Physiol 57: 560-563.

Nascimento HC, Marenco RA (2013). Mesophyll conductance variations in response to diurnal environmental factors in Myrcia paivae and Minquartia guianensis in Central Amazonia. Photosynthetica 51: 457-464.

Nebauer SG, Renau-Morata B, Guardiola JL, Molina RV (2011) Photosynthesis downregulation precedes carbohydrate accumulation under sink limitation in Citrus. Tree Physiol 31: 169-177.

Nikinmaa E, Hölttä T, Hari P, Kolari P, Mäkelä A, Sevanto S, Vesala T (2013) Assimilate transport in phloem sets conditions for leaf gas exchange. Plant Cell Environ 36: 655-669.

Pantin F, Simonneau T, Muller B (2012) Coming of leaf age: control of growth by hydraulics and metabolics during leaf ontogeny. New Phytol 196: 349-366.

Pammenter NW, Van der Willigen C (1998) A mathematical and statistical analysis of the curves illustrating vulnerability of xylem to cavitation. Tree Physiol 18: 589-593.

Patrick JW (2013) Does Don Fisher's high-pressure manifold model account for phloem transport and resource partitioning?. Frontiers in plant science 4.

Paul MJ, Foyer CH (2001) Sink regulation of photosynthesis. J Exp Bot 52: 1383-1400.

Paul MJ, Pellny TK (2003). Carbon metabolite feedback regulation of leaf photosynthesis and development. J Exp Bot 5: 539-547.

Pfautsch S, Renard J, Tjoelker MG, Salih A (2015) Phloem as Capacitor: Radial Transfer of Water into Xylem of Tree Stems Occurs via Symplastic Transport in Ray Parenchyma. 
Prentice IC, Dong N, Gleason SM, Maire V, Wright IJ (2014) Balancing the costs of carbon gain and water transport: testing a new theoretical framework for plant functional ecology. Ecol Lett 17: 82-91.

Porcar-Castell A, Tyystjärvi E, Atherton J, van der Tol C, Flexas J, Pfündel EE, ..., Berry JA (2014) Linking chlorophyll a fluorescence to photosynthesis for remote sensing applications: mechanisms and challenges. J Exp Bot 65: 4065-4095

Quentin AG, Close DC, Hennen LMHP, Pinkard EA (2013). Down-regulation of photosynthesis following girdling, but contrasting effects on fruit set and retention, in two sweet cherry cultivars. Plant Physiol Biochem 73: 359-367.

Sevanto S, McDowell NG, Dickman LT, Pangle R, Pockman WT (2014) How do trees die? A test of the hydraulic failure and carbon starvation hypotheses. Plant Cell Environ 37: 153-161.

Sharkey TD, Bernacchi CJ, Farquhar, GD, Singsaas EL (2007) Fitting photosynthetic carbon dioxide response curves for C3 leaves. Plant Cell Environ 3: 1035-1040.

Sperry JS, Alder NN, Eastlack SE (1993) The effect of reduced hydraulic conductance on stomatal conductance and xylem cavitation. J Exp Bot 44: 1075-1082.

Steppe K, Sterck F, Deslauriers A (2015) Diel growth dynamics in tree stems: linking anatomy and ecophysiology. Trends Plant Sci 20: 335-343.

Thompson MV, Holbrook NM (2003) Application of a single-solute non-steady-state phloem model to the study of long-distance assimilate transport. J Theor Biol 220: 419-455

Turgeon R (2010) The role of phloem loading reconsidered. Plant Physiol 152: 1817-1823.

Turnbull MH, Murthy R, Griffin KL (2002) The relative impacts of daytime and night-time warming on photosynthetic capacity in Populus deltoides. Plant Cell Environ 25: $1729-1737$.

Tuzet A, Perrier A, Leuning R (2003) A coupled model of stomatal conductance, photosynthesis and ranspiration. Plant Cell Environ 26: 1097-1116.

Tyree MT, Sperry JS (1988) Do woody plants operate near the point of catastrophic xylem dysfunction caused by dynamic water stress? Answers from a model. Plant Physiol 88: 574580.

Woodruff DR (2014) The impacts of water stress on phloem transport in Douglas-fir trees. Tree Physiol 34: 5-14.

Wullschleger SD (1993) Biochemical limitations to carbon assimilation in C3 plants-a retrospective analysis of the A/Ci curves from 109 species. J Exp Bot 44: 907-920.

Zhang S, Gao R (2000) Diurnal changes of gas exchange, chlorophyll fluorescence, and stomatal aperture of hybrid poplar clones subjected to midday light stress. Photosynthetica, 37: $559-571$. 
Zhou S, Duursma, RA, Medlyn BE, Kelly JWG, Prentice IC (2013) How should we model plant responses to drought? An analysis of stomatal and non-stomatalresponses to water stress. Agric. Forest Meteorol 182: 204-214.

Zhou S, Medlyn B, Sabaté S, Sperlich D, Prentice IC (2014) Short-term water stress impacts on stomatal, mesophyll, and biochemical limitations to photosynthesis differ consistently among tree species from contrasting climates. Tree Physiol 34: 1035-1046.

\section{Tables}

Table 1. List of symbols, environmental drivers and parameters (based on a typical day for Scots pine trees at SMEAR II station in Hyytiälä, Southern Finland, when possible)

\begin{tabular}{|l|l|}
\hline Symbol & Meaning \\
\hline $\boldsymbol{E}$ & leaf area specific transpiration rate $\left(\mathrm{m}^{3} \mathrm{~m}^{-2} \mathrm{~s}^{-1}\right)$ \\
\hline $\boldsymbol{J}_{\boldsymbol{x}}$ & leaf area specific xylem sap flow rate $\left(\mathrm{m}^{3} \mathrm{~m}^{-2} \mathrm{~s}^{-1}\right)$ \\
\hline $\boldsymbol{J}_{\text {soil }}$ & leaf area specific rate of root water uptake from soil $\left(\mathrm{m}^{3} \mathrm{~m}^{-2} \mathrm{~s}^{-1}\right)$ \\
\hline $\boldsymbol{A}$ & leaf area specific $\mathrm{CO}_{2}$ assimilation rate $\left(\mathrm{mol} \mathrm{m}^{-2} \mathrm{~s}^{-1}\right)$ \\
\hline $\boldsymbol{J}_{p}$ & leaf area specific phloem sap flow rate $\left(\mathrm{mol} \mathrm{m}^{-2} \mathrm{~s}^{-1}\right)$ \\
\hline $\boldsymbol{U}$ & leaf area specific phloem unloading rate of sugars $\left(\mathrm{mol} \mathrm{m}^{-2} \mathrm{~s}^{-1}\right)$ \\
\hline $\boldsymbol{\Psi}_{\text {leaf }}$ & leaf water potential (MPa) \\
\hline $\boldsymbol{\Psi}_{\text {root }}$ & root water potential (MPa) \\
\hline $\boldsymbol{\Psi}_{\text {soil }}$ & soil water potential (MPa) \\
\hline $\boldsymbol{C}_{\text {leaf }}$ & leaf phloem sugar concentration $\left(\mathrm{mol} \mathrm{m} \mathrm{m}^{-3}\right)$ \\
\hline $\boldsymbol{C}_{\text {sink }}$ & sink phloem sugar concentration $\left(\mathrm{mol} \mathrm{m} \mathrm{m}^{-3}\right)$ \\
\hline $\boldsymbol{P}_{\text {leaf }}$ & leaf phloem turgor pressure $(\mathrm{MPa})$ \\
\hline $\boldsymbol{P}_{\text {sink }}$ & sink phloem turgor pressure (MPa) \\
\hline
\end{tabular}




\begin{tabular}{|l|l|}
\hline $\boldsymbol{g}$ & stomatal conductance $\left(\mathrm{mol} \mathrm{m}^{-2} \mathrm{~s}^{-1}\right)^{* *}$ \\
\hline $\boldsymbol{F}_{\boldsymbol{m o l}-\boldsymbol{m} 3}$ & unit conversion factor $\left(18^{*} 10^{-6} \mathrm{~m}^{3} \mathrm{~mol}^{-1}\right)$ \\
\hline $\boldsymbol{K}_{\boldsymbol{x}}$ & xylem hydraulic conductance $\left(\mathrm{m} \mathrm{Pa}^{-1} \mathrm{~s}^{-1}\right)$ \\
\hline $\mathbf{K}_{\text {soil }}$ & soil hydraulic conductance $\left(\mathrm{m} \mathrm{Pa}^{-1} \mathrm{~s}^{-1}\right)$ \\
\hline $\mathbf{K}_{\text {tot }}$ & relative decrease in $A$ due to non-stomatal limitations (unit less) \\
\hline $\boldsymbol{\phi}$ & leaf internal $\mathrm{CO}_{2}$ concentration $\left(\mathrm{ppm}^{2}\right)$ \\
\hline $\boldsymbol{C}_{\boldsymbol{i}}$ & a physical constant $\left(8.314 \mathrm{~J} \mathrm{~K}^{-1} \mathrm{~mol}^{-1}\right)$ \\
\hline $\boldsymbol{R}$ & temperature $(300 \mathrm{~K})^{* * * *}$ \\
\hline $\boldsymbol{T}$ & viscosity of phloem sap (unit less) \\
\hline $\boldsymbol{\eta}$ & \\
\hline
\end{tabular}

*Expressed in relation to pure water $\left(0.001 \mathrm{~Pa}^{*} \mathrm{~s}\right)$, for phloem viscosity is calculated as a function of phloem sugar concentration.

${ }^{* *}$ Expressed per total leaf area (and not projected leaf area) for $\mathrm{CO}_{2}$. The conductance for water is 1.6 times higher.

$958 \quad{ }^{* * * *} K_{\text {tot }}=\left(K_{x}^{-1}+K_{\text {soil }}{ }^{-1}\right)^{-1}$

\begin{tabular}{|c|c|}
\hline Environmental driver & Base case value \\
\hline $\boldsymbol{C}_{\boldsymbol{a}}$ ambient $\mathrm{CO}_{2}$ concentration & 400ppm \\
\hline $\boldsymbol{d}_{\boldsymbol{w}}$ vapor pressure deficit (VPD) & $0.01 \mathrm{~mol} \mathrm{~mol}^{-1}$ \\
\hline I light intensity (PAR) & $200 \mu \mathrm{mol} \mathrm{m}^{-2} \mathrm{~s}^{-1}$ \\
\hline$\Psi_{\text {soil }}$ soil water potential & $-0.1 \mathrm{MPa}$ \\
\hline
\end{tabular}

\begin{tabular}{|l|l|}
\hline Parameter & Base case value \\
\hline $\boldsymbol{\Psi}_{\boldsymbol{P} L C 50} \psi$ at which half of xylem conductance is lost & $-3 \mathrm{MPa}(\mathrm{Cochard}$ et al. 2005) \\
\hline $\boldsymbol{A}_{\boldsymbol{c}}$ slope of the xylem vulnerability curve & $2 * 10^{-6} \mathrm{~Pa}^{-1}$ (Estimated) \\
\hline $\boldsymbol{K}_{\boldsymbol{x}, \boldsymbol{0}}$ leaf-area specific xylem conductance & $4^{*} 10^{-13} \mathrm{~m} \mathrm{~Pa}^{-1} \mathrm{~s}^{-1^{*}}$ \\
\hline $\boldsymbol{K}_{\boldsymbol{p}}$ leaf-area specific phloem conductance & $3 * 10^{-14} \mathrm{~m} \mathrm{~Pa}^{-1} \mathrm{~s}^{-1^{*}}$ \\
\hline
\end{tabular}




\begin{tabular}{|l|l|}
\hline $\boldsymbol{K}_{\text {soilsat }}$ hydraulic conductance of saturated soil & $3^{*} 10^{-6} \mathrm{~m}^{3} \mathrm{~Pa}^{-1} \mathrm{~s}^{-1}$ (Duursma et al. 2008) \\
\hline $\boldsymbol{\Psi}_{\boldsymbol{e}}$ soil parameter & $-0.68 \mathrm{kPa}$ (Duursma et al. 2008) \\
\hline $\boldsymbol{a}_{\text {soil }}$ soil parameter & $2.7(\mathrm{Duursma}$ et al. 2008) \\
\hline $\boldsymbol{\alpha}_{\text {sink }}$ and $\boldsymbol{\beta}_{\text {sink }}$ sink parameters & $5^{*} 10^{-5} \mathrm{~mol} \mathrm{~s}^{-1}$ and $500 \mathrm{~mol} \mathrm{~m}^{-3 * *}$ \\
\hline $\boldsymbol{C o} C_{\text {leaf }}$ at which photosynthesis goes to zero & $1500 \mathrm{~mol} \mathrm{~m}^{-3^{* * *}}$ \\
\hline $\boldsymbol{V}_{\boldsymbol{c} \text { max }}$ Farquhar photosynthesis model parameter & $50 * 10^{-6} \mathrm{~mol} \mathrm{~m}^{-2} \mathrm{~s}^{-1^{* * * *}}$ \\
\hline $\boldsymbol{J}_{\boldsymbol{m a x}}$ Farquhar photosynthesis model parameter & $110^{*} 10^{-6} \mathrm{~mol} \mathrm{~m}^{-2} \mathrm{~s}^{-1^{* * * *}}$ \\
\hline $\boldsymbol{\Gamma}$ Farquhar photosynthesis model parameter & $38 \mathrm{ppm}$ \\
\hline $\boldsymbol{O}$ Farquhar photosynthesis model parameter & $210000 \mathrm{ppm}$ \\
\hline $\boldsymbol{K}_{\boldsymbol{o}}$ Farquhar photosynthesis model parameter & $420000 \mathrm{ppm}$ \\
\hline $\boldsymbol{K}_{\boldsymbol{c}}$ Farquhar photosynthesis model parameter & $275 \mathrm{ppm}$ \\
\hline $\boldsymbol{\theta}$ Farquhar photosynthesis model parameter & 0.5 \\
\hline $\boldsymbol{q}$ Farquhar photosynthesis model parameter & 0.14 \\
\hline
\end{tabular}

"Based on Nikinmaa et al. (2013)

${ }^{* *}$ Chosen so that sink osmotic concentration would be reasonable, $\sim 300 \mathrm{~mol} \mathrm{~m}^{-3}$ which we have typically measured on Scots pine trees (unpublished)

**** Laboratory measurements on seedlings showed $\sim 1000 \mathrm{~mol} \mathrm{~m}^{-3}$ (see Fig. 2a), but this was increased to $1500 \mathrm{~mol} \mathrm{~m}^{-3}$ to match field observations

***** Based on Kolari et al. (2014) for Scots pine trees

\section{Figure legends}

Fig. 1. Connections between source, transport and sink processes, and the governing equations used in the model. A: Expressed in mathematical relations, and B: drawn as graphs.

Fig. 2. A: Measured relations between leaf osmotic osmolality and the ratio between photosynthesis rate $(A)$ and leaf internal $\mathrm{CO}_{2}$ concentration $C_{i}$. B: Measured relations between leaf water potential and the ratio between photosynthesis rate $(A)$ and leaf internal $\mathrm{CO}_{2}$ concentration $C_{i}$.

Fig. 3. Model behaviour as a function of stomatal conductance in terms of A: photosynthetic production, B: phloem transport, $\mathbf{C}$ : sink sugar utilization, using base case parameterization shown in Table 1. 
Fig. 4. A schematic figure of the photosynthesis rate as a function of leaf internal $\mathrm{CO}_{2}$ concentration $C_{i}$ when ambient $\mathrm{CO} 2$ concentration is held constant. 990 Stomatal opening increases $C_{i}$ and causes movement along any $A-C_{i}$ curve $(\phi=$ $9911, \phi=0.8$ or $\phi=0.6$ ) to the upper right diagonal direction. Stomatal opening 992 simultaneously causes $\phi$ to decrease thus forcing a movement to a lower $A-C_{i}$ 993 curve.

994

Fig. 5. A: The value of stomatal conductance which maximizes the sustainable metabolic rate (i.e. the simultaneous photosynthesis, phloem transport and sink sugar utilization rate) predicted by the model as a function of soil water potential $\left(\psi_{\text {soil }}\right)$, VPD, light level (PAR), ambient $\mathrm{CO}_{2}$ concentration $\left(C_{a}\right)$, and B: xylem hydraulic conductance $\left(K_{x}\right)$, phloem hydraulic conductance $\left(K_{p}\right)$, leaf sugar concentration at which photosynthesis goes to zero $\left(C_{o}\right), \psi_{\mathrm{PLC50}}$ and leaf area $\left(A_{\text {leaf }}\right)$. Each parameter was varied independently while the others were kept at their base case values. When $\psi_{\text {PLC50 }}$ was varied, the value of the parameter $a_{x y l e m}$ in Equation 7 (the slope of the vulnerability curve) was also changed in inverse proportion to retain the proportionality between these two parameters.

Fig. 6. Model behaviour when source strength ( $\alpha$ in Equation 4$)$ and sink strength $\left(\alpha_{\operatorname{sink}}\right.$ in Equation 9$)$ are varied simultaneously: $\mathbf{A}$ and B: stomatal conductance maximizing metabolic rate, $\mathbf{C}$ and $\mathbf{D}$ : the maximum sustainable metabolic rate, and $\mathbf{E}$ and $\mathbf{F}$ : leaf osmotic potential (e and f).

Fig. 7. Comparison of our model behaviour with the unified stomatal control model (e.g. Medlyn et al. 2011) when PAR (I), $C_{a}$ and VPD $\left(d_{w}\right)$ are varied simultaneously using different values for soil-to-leaf hydraulic conductance $\left(K_{t o t}\right)$. The values for all of the other parameters were kept as in the previous simulations, i.e. the base case values shown in Table 1.

Fig. 8. A: Comparison of our model behaviour with the optimal stomatal control model (e.g. Medlyn et al. 2011) when PAR $(I)$ and VPD $\left(\mathrm{d}_{\mathrm{w}}\right)$ are varied simultaneously using different values for soil-to-leaf hydraulic conductance $\left(K_{t o t}\right)$. The values for all of the other parameters were kept as in the previous simulations, i.e. the base case values shown in Table 1. B: The same as A, but now the prediction by the optimal stomatal control model was multiplied by $\phi$ to account for the changes in non-stomatal limitations to photosynthesis. 
1031 Fig. 1

A

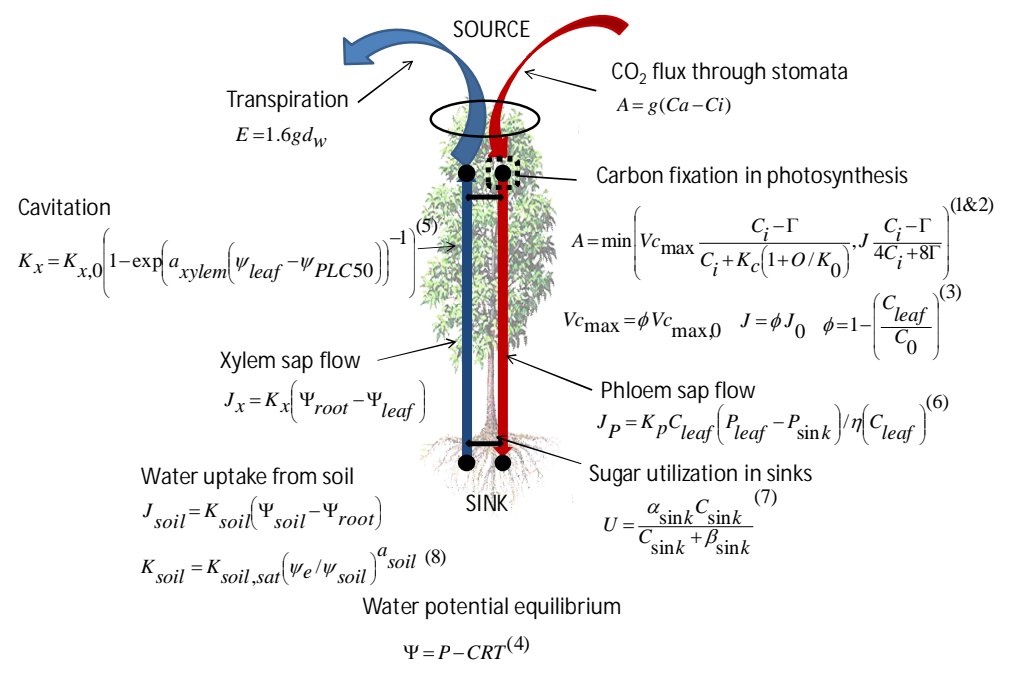

B

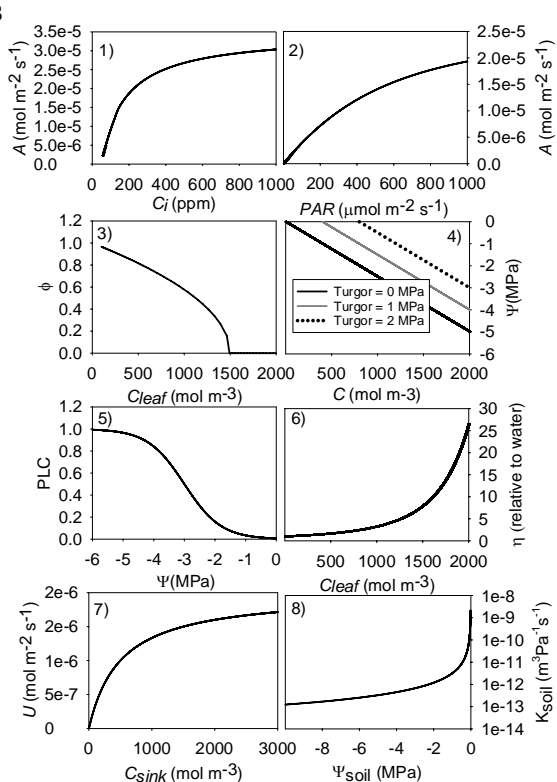


Fig. 2

1067

1068

1069
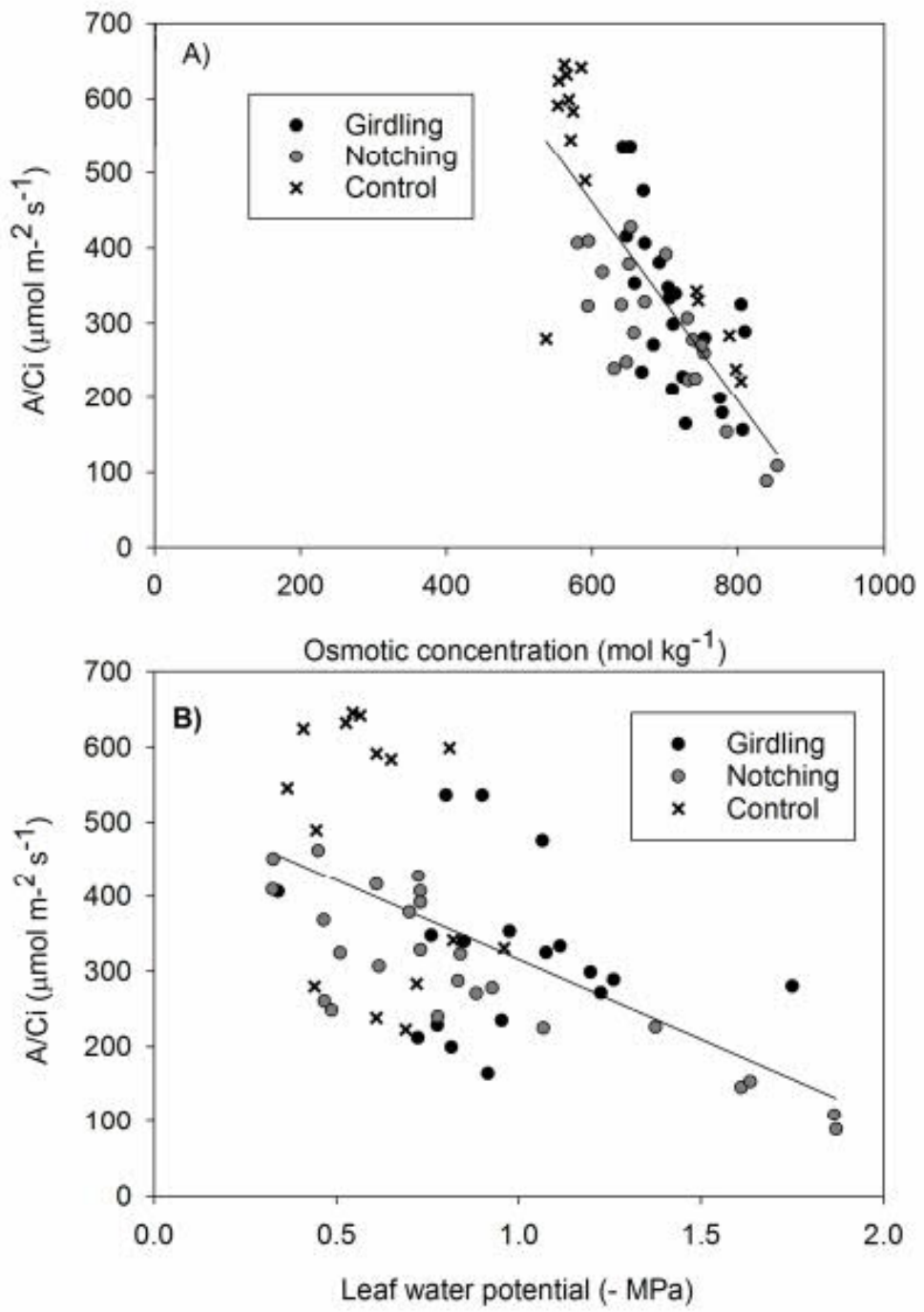

1070 Fig. 3.

1071

1072

1073 

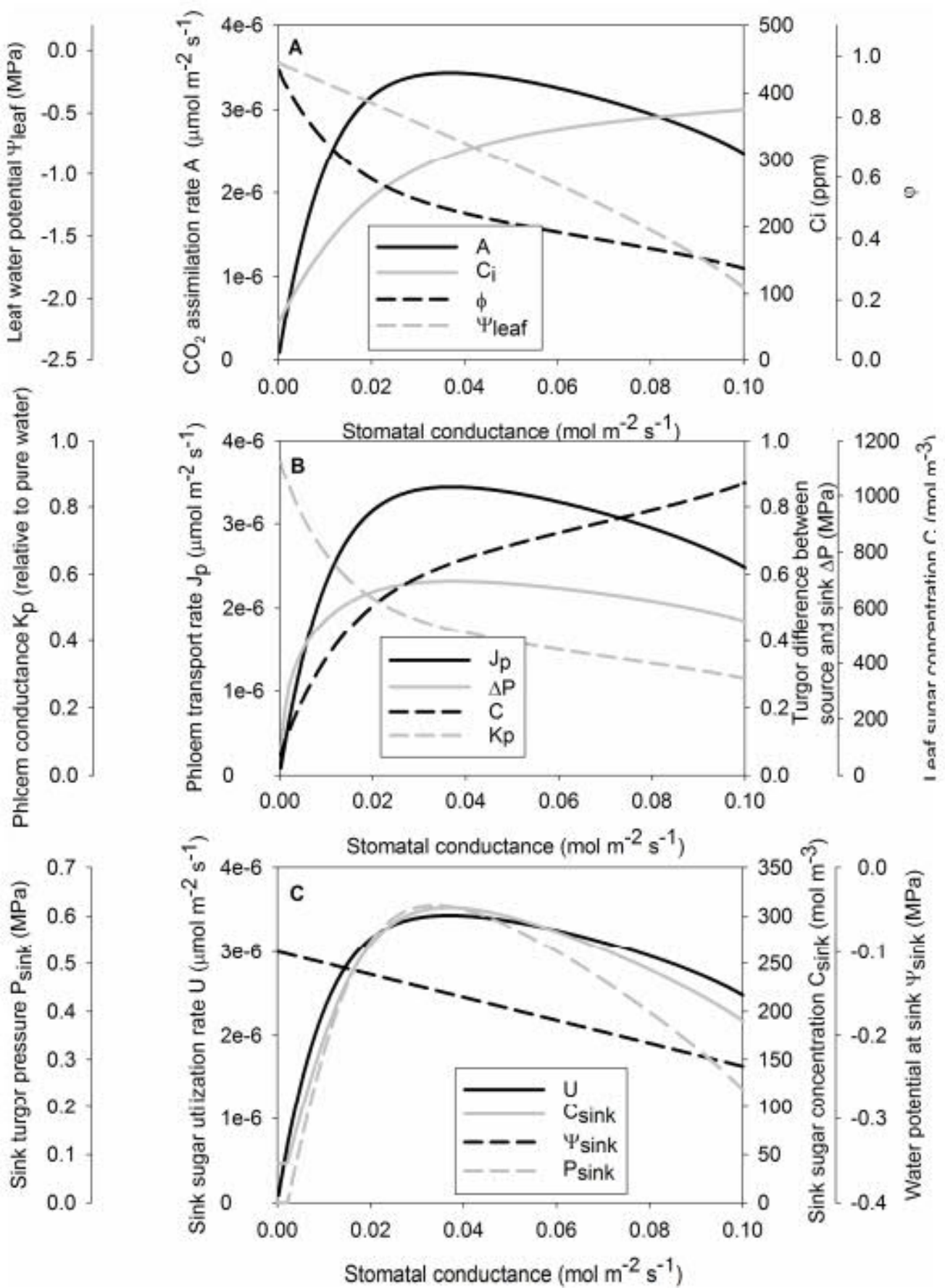

Fig. 4. 


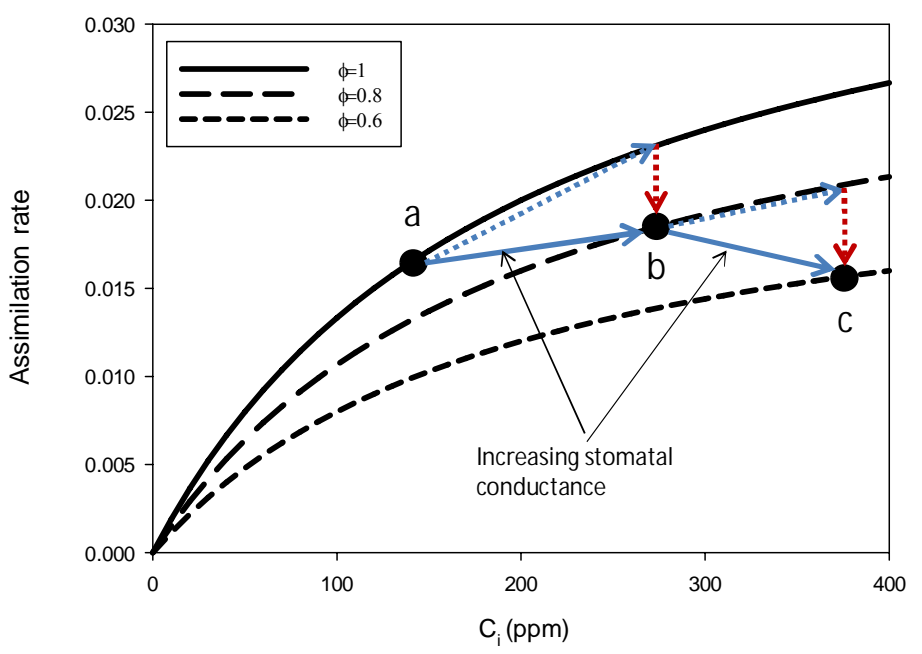

Fig. 5.

1085

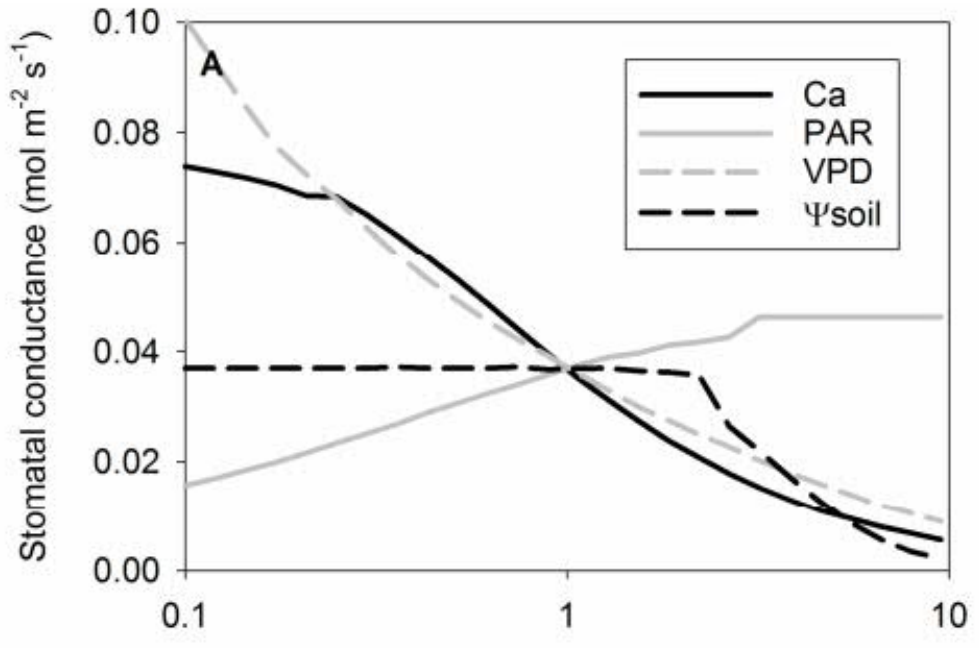

Value in relation to base case

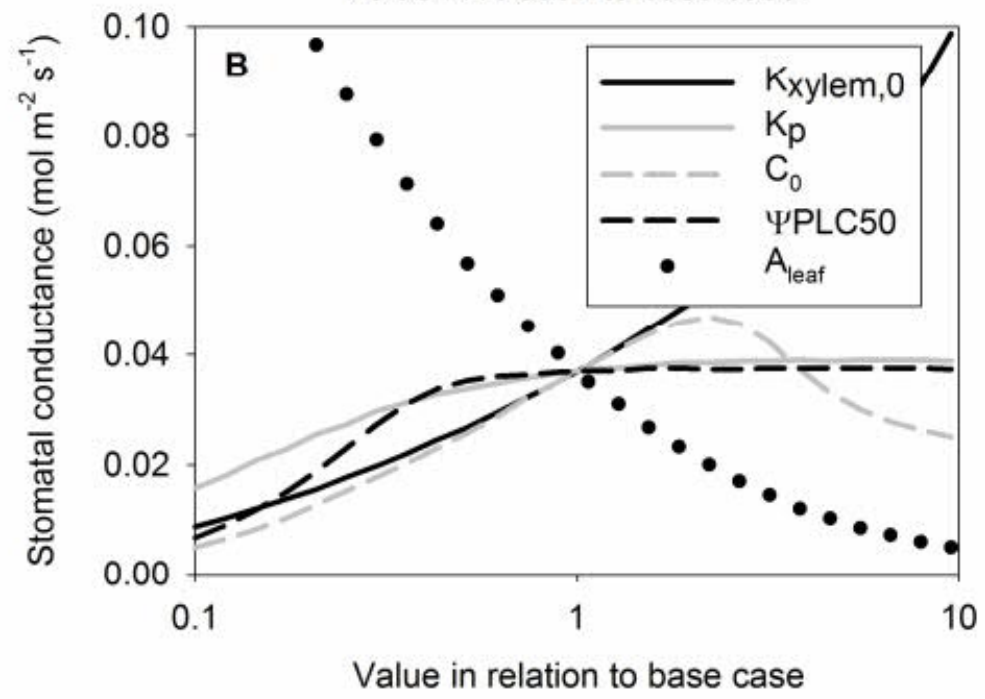


Fig. 6 .

1089

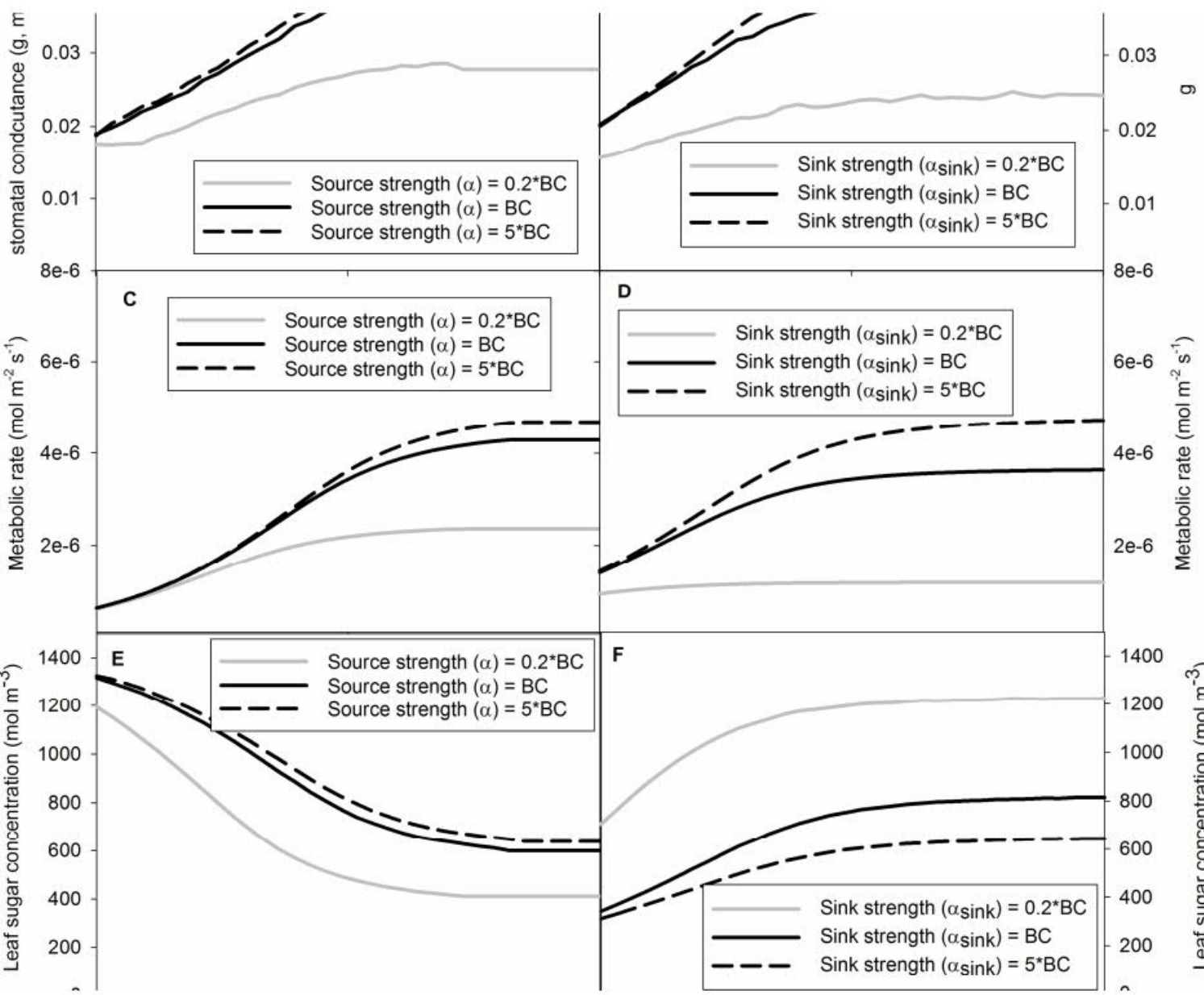

1092

1093

Fig. 7.

1094

1095

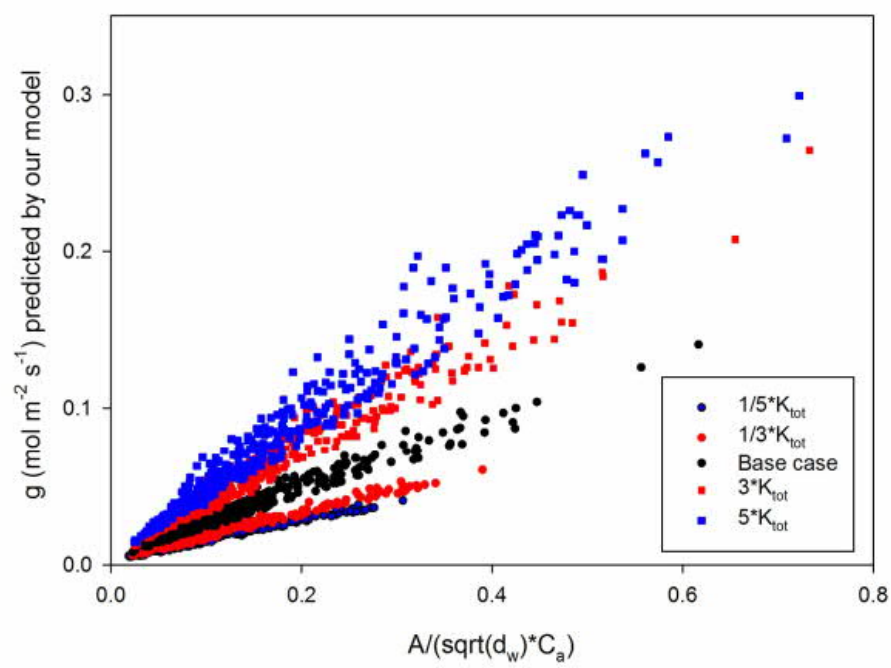

Fig. 8. 

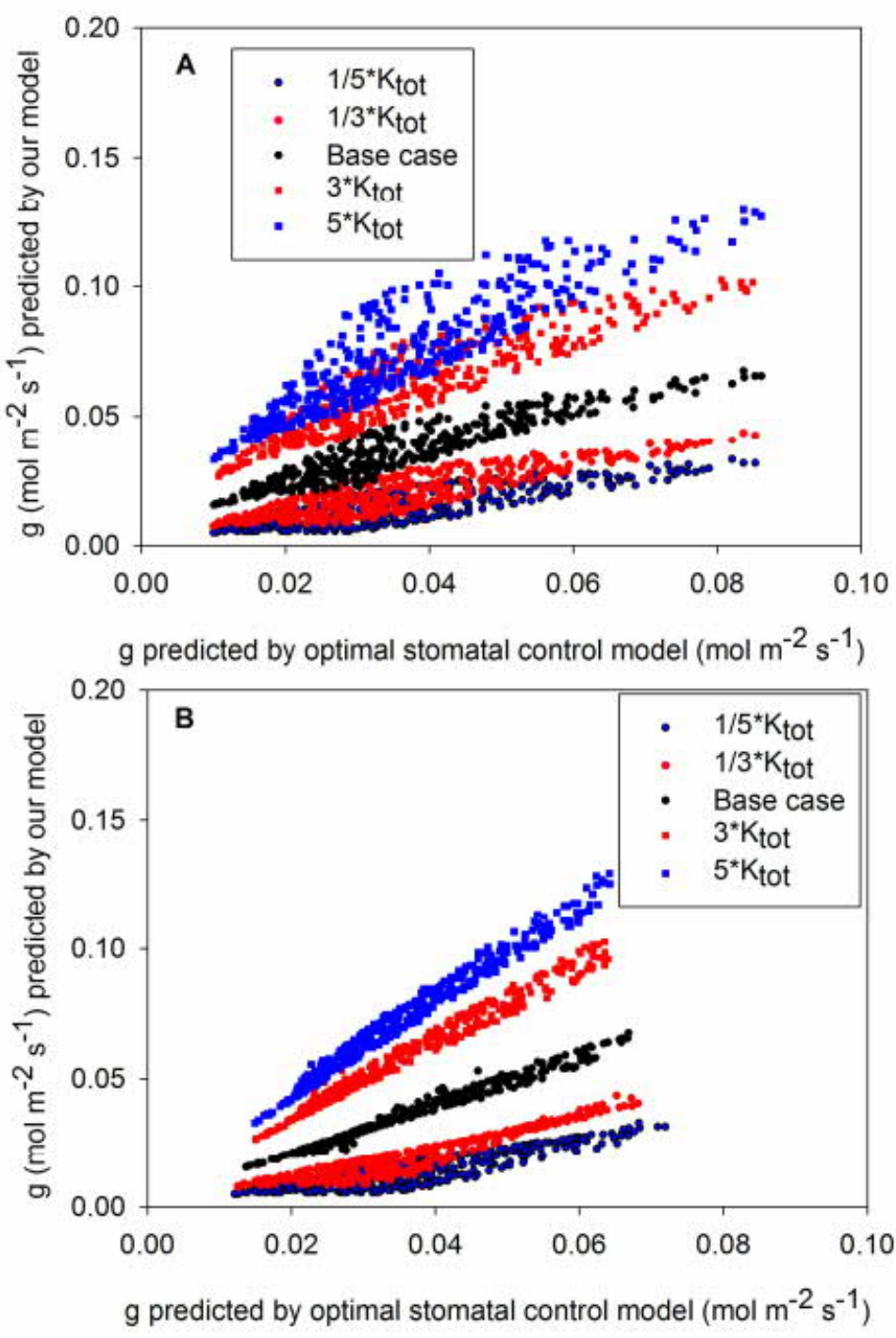